\title{
Erratum to: No association between polymorphisms of peroxisome proliferator-activated receptor-gamma gene and peak bone mineral density variation in Chinese nuclear families
}

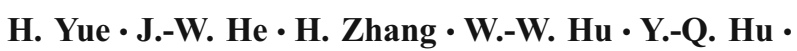 \\ M. Li • Y.-J. Liu $\cdot$ S.-H. Wu $\cdot$ Z.-L. Zhang
}

Received: 2 February 2010 / Accepted: 3 February 2010/Published online: 19 March 2010

(C) International Osteoporosis Foundation and National Osteoporosis Foundation 2010

\section{Erratum to: Osteoporos Int \\ DOI 10.1007/s00198-009-1028-5}

The word "peroxisome" was missing from the term "peroxisome proliferator-activated receptor-gamma" in four places: the article title, the first sentence of the Abstract, the Keywords, and the first sentence of the second paragraph of the Introduction.

The online version of the original article can be found under http://dx. doi.org/10.1007/s00198-009-1028-5.

H. Yue · J.-W. He $\cdot$ H. Zhang $\cdot$ W.-W. Hu • Y.-Q. Hu • M. Li •

Y.-J. Liu $\cdot$ Z.-L. Zhang $(\bowtie)$

The Department of Osteoporosis,

Metabolic Bone Disease and Genetic Research Unit, Shanghai

Jiao Tong University Affiliated Sixth People's Hospital,

Shanghai, 600 Yi-Shan Rd,

Shanghai 200233, People's Republic of China

e-mail: ZZL2002@medmail.com.cn

H. Yue $\cdot$ S.-H. Wu

The Department of Endocrinology and Metabolism, Shanghai

Clinical Center for Diabetes,

Shanghai Jiao Tong University Affiliated Sixth People's Hospital,

Shanghai Diabetes Institute, Shanghai Key Laboratory Mellitus,

Shanghai, People's Republic of China 